\title{
Type 2 (non-insulin-dependent) diabetes mellitus associated with a mutation of the glucokinase gene in a Japanese family
}

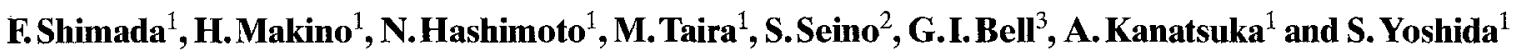 \\ ${ }^{1}$ Second Department of Internal Medicine, Chiba, Japan \\ ${ }^{2}$ The Center for Neurobiology and Molecular Immunology, Chiba University School of Medicine, Chiba, Japan, \\ ${ }^{3}$ Howard Hughes Medical Institute and Department of Biochemistry and Molecular Biology and Medicine, University of Chicago, \\ Chicago, Illinois, USA
}

\begin{abstract}
Summary. Mutations were screened for in the glucokinase gene of 25 Japanese patients with Type 2 (non-insulin-dependent) diabetes mellitus. Each exon was scanned by electrophoresis of enzymatically amplified DNA segments under non-denaturing conditions and variants were sequenced. A variant pattern was detected in exon 5 of one patient. Direct sequencing of this exon revealed a single nucleotide substitution in codon 188 (GCT $\rightarrow$ ACT) of one of two alleles resulting in the mutation of $\mathrm{Ala}^{188} \rightarrow \mathrm{Thr}$, an invariant residue in the sequence of all mammalian glucokinases and hexokinases. This mutation was not found in 40 normal control subjects. The proband had been diagnosed with Type 2 diabetes at the age of 62 years. Four other members of her family have the same mutation and all have Type 2 diabetes or impaired glucose tolerance. The youngest age at diagnosis of Type 2 diabetes in these other members was 13 years, suggesting
\end{abstract}

that her pedigree was maturity-onset diabetes of the young (MODY). All subjects with the $\mathrm{Thr}^{188}$ mutation show a decreased insulin secretory response during oral glucose tolerance testing. Mutations in the glucokinase gene associated with Type 2 diabetes have been previously identified in Caucasian (French and British) subjects. This study indicates that mutations in this gene are also implicated in the development of Type 2 diabetes in Asians. Further studies are required to determine the frequency of mutations in glucokinase among Japanese patients with Type 2 diabetes.

Key words: Glucokinase gene, mutation, Type 2 (non-insulin-dependent) diabetes mellitus, polymerase chain reaction, single stranded conformation polymorphism, insulin secretion.
Type 2 (non-insulin-dependent) diabetes mellitus is a heterogeneous disorder of glucose homeostasis characterized by defects in insulin secretion and insulin action [1, 2]. The familial aggregation and high concordance rate in identical twins indicate the important contribution of heredity to its development [3]. A number of genes whose mutation can increase the risk of developing Type 2 diabetes have been identified including the glucokinase gene on chromosome 7 [4-8], the insulin gene on chromosome $11[9,10]$, the insulin receptor gene on chromosome 19 [11], and a gene of unknown structure and function on chromosome 20 [12]. In addition, mutations in the mitochondrial genome have been implicated in a maternally inherited disorder characterized by Type 2 diabetes and deafness $[13,14]$.

Recent studies of French and British families with early-onset Type 2 diabetes or maturity-onset diabetes of the young (MODY) have resulted in the identification of one nonsense (polypeptide chain terminating) and three different missense (amino acid replacement) mutations in the glucokinase gene that cosegregate with Type 2 diabetes in four French and two British families $[5,7,8]$. Interestingly, the same mutation was found in the two unrelated British families, one of which had MODY whereas the other was considered to have late-onset Type 2 diabetes [8]. The studies of patients with Type 2 diabetes due to the presence of a mutation in glucokinase gene indicate that they have a relatively mild form of Type 2 diabetes with onset often during childhood and an autosomal dominant mode of inheritance.

Here, we report the identification of a mutation in exon 5 of glucokinase gene that cosegregates with Type 2 diabetes or impaired glucose tolerance in a Japanese family. This mutation, $\mathrm{Ala}^{188} \rightarrow \mathrm{Thr}$, is an amino acid that does not vary among the sequences of mammalian glucokinases and hexokinases [15-17] and is located in a region of glucokinase that undergoes a major conformational change on glucose binding [18]. 


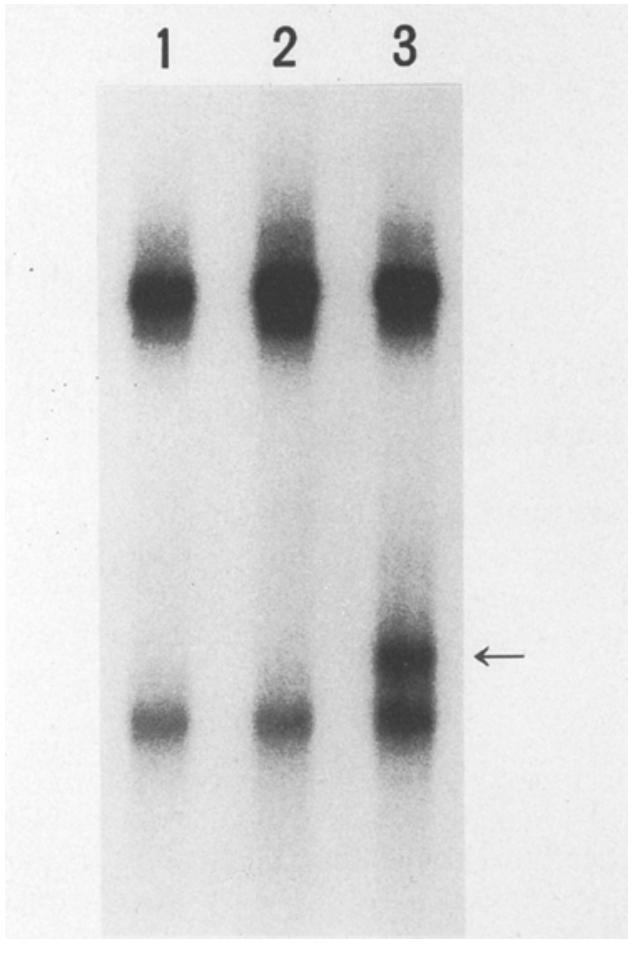

Fig.1. Single stranded conformation polymorphism analysis of exon 5 of two normal control subjects (lanes 1 and 2) and the proband (lane 3). Exon 5 was amplified in vitro and the product diluted and then electrophoresed in non-denaturing polyacrylamide $(0 \%$ glycerol) gel at $4^{\circ} \mathrm{C}$. The variant band in the proband is indicated by the arrow

\section{Subjects and methods}

The study population consisted of 25 Type 2 diabetic patients. Thirteen of the patients had been diagnosed with Type 2 diabetes prior to 25 years of age (age at study: $20 \pm 2.0$ years, age at diagnosis: $16 \pm 1.4$ years, BMI: $22.2 \pm 0.6 \mathrm{~kg} / \mathrm{m}^{2}$ ) and of these six had a family history of Type 2 diabetes. The remaining 12 patients were diagnosed with Type 2 diabetes after 25 years of age (age at study: $57 \pm 2.9$ years, age at diagnosis: $42 \pm 3.0$ years, BMI: $20.2 \pm 0.7 \mathrm{~kg} / \mathrm{m}^{2}$ ) and seven of these had a family history of diabetes. Type 2 diabetes was diagnosed according to WHO criteria [19]. We also screened 40 normal control subjects for mutations in exon 5 of the glucokinase gene. All patients were informed of the aim of the study and gave their informed consent. This work was approved by the ethical committee of the Chiba University Hospital.

\section{Oral glucose tolerance test}

A standard 75-g oral glucose tolerance test was carried out on the proband, four affected and one unaffected member of her family, and eight normal control subjects. The age and BMI of the nondiabetic control subjects (age: $42 \pm 5.0$ years, BMI: $21.5 \pm 1.5 \mathrm{~kg} / \mathrm{m}^{2}$ ) were matched to those of the patients (age: $50 \pm 7.6$ years, BMI: $\left.20.0 \pm 1.8 \mathrm{~kg} / \mathrm{m}^{2}\right)$.

\section{Identification of mutations}

DNA was prepared from peripheral blood lymphocytes. Each exon of glucokinase gene was amplified using polymerase chain reaction (PCR) as described [7]. The PCR products were diluted 15-fold with formamide buffer ( $95 \%$ formamide, $0.05 \%$ blomophenol blue and $0.05 \%$ xylene cyanol), heated at $95^{\circ} \mathrm{C}$ for $3 \mathrm{~min}$ and $1.5 \mu \mathrm{l}$ of each sample was loaded onto $5 \%$ non-denaturing polyacrylamide gel ( $30 \mathrm{~cm} \times 40 \mathrm{~cm} \times 0.03 \mathrm{~cm}$; acrylamide: $N, N^{\prime}$-methylene-bis-acrylamide $=49: 1)$ [20]. Each sample was run on four gels containing 0 or $10 \%$ glycerol at room temperture or $4^{\circ} \mathrm{C}$. The gels were then transferred to paper, dried and exposed to film (XAR-5, Kodak Rochester, N. Y., USA) with intensifying screen for $12 \mathrm{~h}$ at $-70^{\circ} \mathrm{C}$. The sequence of the amplified DNA was determined directly as previously reported [21, 22]. In addition, the PCR products were also cloned into M13 and sequenced using a Sequenase DNA Sequencing Kit (United States Biochemical Corporation, Cleveland, Ohio, USA). All mutations are described relative to the amino acid sequence of the beta-cell isoform of glucokinase [8].

\section{Statistical analysis}

Statistical significance was evaluated using an unpaired Student's $t$-test. Data are given as mean \pm SEM.

\section{Results}

All 12 exons of the glucokinase gene of 25 Type 2 diabetic patients were amplified using PCR and analysed by single stranded conformation polymorphism (SSCP). A variant pattern was noted in only one of the 25 patients (Fig.1) and was consistent with the presence of alleles of exon 5 of both normal and abnormal sequence. The patient in which the abnormal SSCP pattern was seen was a 68 -year-old Japanese women who was diagnosed with Type 2 diabetes at the age of 62 years by physical examination and referred to our hospital. At the time of diagnosis, she had a fasting plasma glucose level of $7.0 \mathrm{mmol} / \mathrm{l}$, and $11.2 \mathrm{mmol} / \mathrm{h}, 2 \mathrm{~h}$ after an oral glucose load. Her BMI at that time was $22.5 \mathrm{~kg} / \mathrm{m}^{2}$. She has subsequently been treated with diet and now has impaired glucose tolerance (IGT) based upon the results of her most recent oral glucose tolerance test. She also has a family history of Type 2 diabetes. Abnormal conformers of exon 5 were not seen in any of the other 24 Type 2 diabetic patients or in a panel of 40 normal subjects.

Sequence of exon 5 showed that the variant pattern resulted from a mutation in codon 188 resulting in the replacement of Ala (GCT) by Thr (ACT) (Fig.2). This mutation occurs within the context of a $\mathrm{CpG}$ dinucleotide (GACGCT $\rightarrow$ GACACT) suggesting that this site may be a "hot spot" for mutation [23]. As shown in Figure 2, the patient is heterozygous at this site and thus expresses both normal and mutant forms of glucokinase. In addition to direct sequencing of the PCR product, the sequence of the mutation was confirmed by reamplification of exon 5 and sequencing the PCR products after subcloning into M13 (data not shown).

SSCP analysis of exon 5 in other members of the patient's family revealed the presence of the variant pattern in four additional individuals (Fig.3). We also confirmed that these four subjects have the Thr ${ }^{188}$ mutation by direct sequence. The clinical features and results of oral glucose tolerance testing of the proband and other subjects with the $\operatorname{Thr}^{188}$ mutation are shown in Table 1 and Table 2 . Based upon the results of the oral glucose tolerance test, 


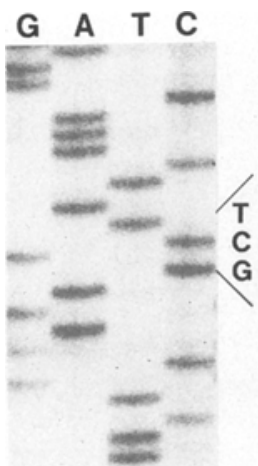

Control

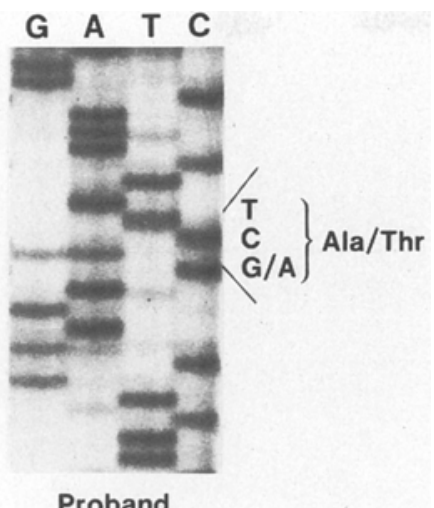

Proband
Fig. 2. Sequence of exon 5 of a normal control subject (left) and the proband (right). Exon 5 was amplified and directly sequenced. Note the presence of two sequences in the proband at the site of the mutation; one sequence is derived from the normal allele and the other from the mutant allele. The $\mathrm{G} \rightarrow \mathrm{A}$ transition in codon 188 resulting in the Ala $\rightarrow$ Thr mutation is shown
I

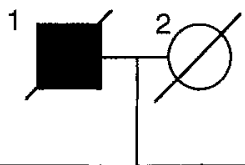

II

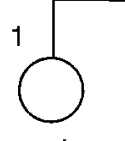

nd
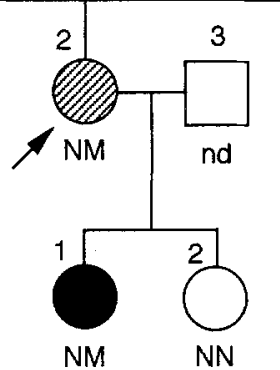

NM

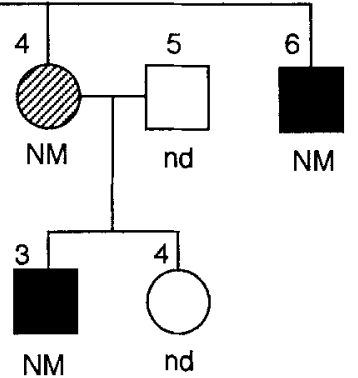

III

Fig. 3. Pedigree of the proband. Roman numbers on the left denote the generation number of arabic number above the symbol denotes each individual within this generation. The symbols are: squares, males; circles, females; symbols with a slash through them, deceased; closed symbols, individuals with Type 2 diabetes; diagonal shading, individuals with impaired glucose tolerance; open symbol, individuals with normoglycaemia; nd denotes individuals who were not available for testing. The proband is noted by an arrow. The exon 5 genotypes are noted under each symbol: $\mathrm{N}$, normal and $\mathrm{M}$, mutant

three of the subjects (II-6, III-1 and III-3) have overt Type 2 diabetes, two (II-2, II-4) have IGT and one individual (III-2) without the mutation showed normal glucose tolerance. One individual (III-3) was diagnosed with Type 2 diabetes at age 13 years whereas four others (II-2, II-4, II-6, III-1) were middle-aged when diagnosed with IGT or Type 2 diabetes. In all individuals with $\mathrm{Thr}^{188}$ mutation, the insulin response to glucose upon oral glucose tolerance testing of these subjects was decreased (Table 2). The insulinogenic index $(\Delta \mathrm{IRI} / \Delta \mathrm{PG}=\mathrm{IRI}$ $30 \mathrm{~min}-I R I 0 \mathrm{~min} / \mathrm{PG} 30 \mathrm{~min}-\mathrm{PG} 0 \mathrm{~min}$, where IRI is immunoreactive insulin and PG is plasma glucose) and insulin level at $30 \mathrm{~min}$ after oral glucose load of the patients were significantly decreased compared with normal control subjects.

\section{Discussion}

We have identified a new missense mutation in the glucokinase gene in a Japanese patients with Type 2 diabetes. This mutation was not seen in 40 unrelated non-diabetic subjects or 24 other selected patients with Type 2 diabetes (13 early-onset and 11 late-onset). In the patient's family, affected members with the mutation have Type 2 diabetes or IGT.

The effect of the $\mathrm{Ala}^{188} \rightarrow \mathrm{Thr}$ mutation on glucokinase activity has not been determined. However, $\mathrm{Ala}^{188}$ is consistent among the sequences of all mammalian hexokinases (hexokinase I-III) and glucokinases [7, 15-17] implying that it serves an important role with respect to the function of these enzymes. Modelling of human pancreatic beta-cell glucokinase on the crystal structure of the open or unliganded form of yeast hexokinase B indicates that $\mathrm{Ala}^{188}$ (equivalent to $\mathrm{Glu}^{195}$ of yeast hexokinase $\mathrm{B}$ ) is located in an alpha-helical surface loop that is quite distant from the active site. However, this region shows changes in conformation between the open and closed forms of yeast hexokinase B [18]. Thus, the mutation of $\mathrm{Ala}^{188} \rightarrow \mathrm{Thr}$ in this region may affect this conformational change and thereby alter the enzymatic properties of glucokinase.

Glucokinase is expressed only in pancreatic beta cells and hepatocytes and plays a key role in their regulation of glucose metabolism $[24,25]$. In the hepatocyte, the phosphorylation of glucose by glucokinase facilitates the uptake and metabolism of glucose by maintaining a gradient for glucose transport. In beta cells, glucokinase controls the flux of glucose through glycolysis and is believed to be, at least in part, the beta-cell glucose sensor controlling the secretion of insulin in response to changes in the blood glucose level. In this respect, Meglasson and Matschinsky [26] have suggested that the levels of glucokinase activity in the beta cell determined the threshold at which it secretes insulin in response to changes in glucose concentration. Previous reports indicated that mutations in glucokinase cause forms of Type 2 diabetes inherited dominantly by a gene dosage mechanism that decreases the levels of glucokinase activity in the beta cell such that the threshold for glucose-stimulated insulin secretion is increased [5-7]. Clinical studies of French patients with glucokinase gene mutations are consistent with this hypothesis [27]. The Japanese patients with the

Table 1. Characteristics of the pedigree and control subjects

\begin{tabular}{lllll}
\hline Patient & $\begin{array}{l}\text { Age at } \\
\text { diagnosis } \\
\text { (years) }\end{array}$ & $\begin{array}{l}\text { Age at } \\
\text { study } \\
\text { (years) }\end{array}$ & $\begin{array}{l}\text { Body mass Current } \\
\text { index } \\
\left(\mathrm{kg} / \mathrm{m}^{2}\right)\end{array}$ & therapy \\
\hline II-2 & 62 & 68 & 22.5 & diet \\
II-4 & 44 & 62 & 16.9 & diet \\
II-6 & 55 & 57 & 25.8 & diet \\
III-1 & 33 & 33 & 18.3 & diet \\
III-3 & 13 & 31 & 16.5 & sulphonylurea \\
Patients & - & $50 \pm 7.6^{\mathrm{a}}$ & $20.0 \pm 1.8^{\mathrm{a}}-$ \\
Control subjects & - & $42 \pm 5.0$ & $21.5 \pm 1.5$ & - \\
\hline
\end{tabular}

${ }^{a}$ Not statistically different compared with control subjects. Data are represented as mean \pm SEM 
Table 2. Plasma glucose and insulin level at 75 -g oral glucose tolerance test

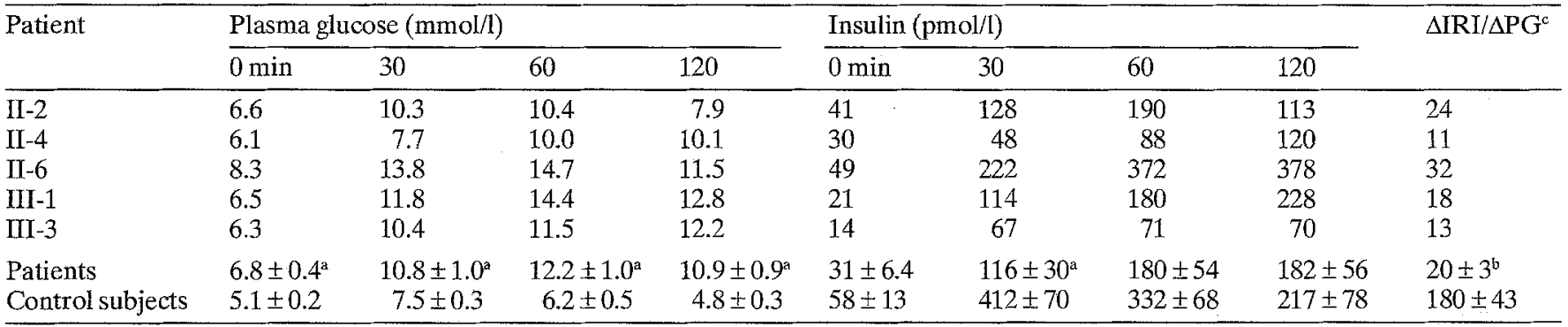

${ }^{\mathrm{a}} p<0.01,{ }^{\mathrm{b}} p<0.05$ vs control subjects; ${ }^{\mathrm{c}} \Delta \mathrm{IRI} / \Delta \mathrm{PG}=\mathrm{IRI} 30 \mathrm{~min}-\mathrm{IRI} 0 \mathrm{~min}$ (pmol/l)/PG $30 \mathrm{~min}-\mathrm{PG} 0 \mathrm{~min}$ (mmol/l) IRI, Immunoreactive insulin; $\mathrm{PG}$, plasma glucose. Data are represented as mean $\pm \mathrm{SEM}$

$\mathrm{Thr}^{188}$ mutation also appear to have a defect in insulin secretion.

Glucokinase gene mutation causes a relatively mild form of diabetes with a spectrum of clinical phenotypes including mild fasting hyperglycaemia, IGT and overt Type 2 diabetes [4-8]. This is also true of the $\mathrm{Thr}^{188}$ mutation described in this family as two individuals with the mutation have IGT and three have overt Type 2 diabetes. Although four of the individuals with the $\mathrm{Thr}^{188}$ were diagnosed at over 25 years of age, the age of diagnosis of one subject was 13 years. These results suggest that this pedigree may be regarded as the MODY pedigree and had they been tested at younger age, the age at diagnosis would have been much lower. However, we could not exclude the possibility that other genetic or environmental factors such as diet contributed to the varied age of onset.

In summary, we have identified a mutation in the glucokinase gene in a Japanese family that resulted in Type 2 diabetes and IGT. Glucokinase gene mutations associated with Type 2 diabetes have now been identified in French and British Caucasian patients and in Japanese. Thus, they do not appear to be restricted to one ethnic or racial group. Thus, more patients need to be studied to determine the frequency of mutations in the glucokinase gene in the Japanese population and the overall contribution to the incidence of Type 2 diabetes.

Acknowledgements. We are indebted to Dr. S. Miyamoto and Dr. N.Sasaki for help in collecting diabetic patients and Dr. Y.Hatanaka, Dr. H. Sano and Dr. T. Miki for clinical assistance. This work was supported in part by Scientific Research Grants 03671131, 02304034 from the Ministry of Education, Science and Culture, Tokyo, Japan, by a grant for Diabetic Research from Otsuka Pharmaceutial Co. Ltd, Tokushima, Japan, by a grant from the Foundation for Growth Science in Japan, by a grant for Cardiovascular Diseases $(3 c-5)$ from the Ministry of Health and Welfare, by a grant from Yamanouchi Foundation for Research on Metabolic Disorders and by the Howard Hughes Medical Institute and National Institutes of Health Diabetes Research and Training Center Grant DK-20595, USA.

\section{References}

1. DeFronzo RA, Bonadonna RC, Ferrannini E (1992) Pathogenesis of NIDDM: a balanced overview. Diabetes Care 15: $318-368$
2. Porte D Jr (1991) $\beta$-cells in type II diabetes mellitus. Diabetes 40: $166-180$

3. Rotter JI, Vadheim CM, Rimoin DL (1990) Genetics of diabetes mellitus. In: Rifkin H, Porte D Jr (eds) Diabetes mellitus, theory and practice, 4th edn. Elsevier, New York, pp 378-413

4. Froguel Ph, Vaxillarie M, Sun F et al. (1992) Close linkage of glucokinase locus on chromosome $7 p$ to early-onset non-insulin-dependent diabetes mellitus. Nature 356: 162-164

5. Vionett N, Stoffel M, Takeda J et al. (1992) Nonsense mutation in the glucokinase gene causes early onset non-insulin-dependent diabetes mellitus. Nature 356: 721-722

6. Hattersley AT, Turner RC, Permutt MA et al. (1992) Linkage of type 2 diabetes to the glucokinase gene. Lancet 339:13071310

7. Stoffel M, Froguel Ph, Takeda J et al. (1992) Human glucokinase gene: isolation, characterization, and identification of two missense mutations linked to early-onset non-insulin-dependent (type 2) diabetes mellitus. Proc Natl Acad Sci USA 89: 76987702

8. Stoffel M, Patel P, Lo Y-MD et al. (1992) Missense glucokinase mutation in maturity-onset diabetes of the young and mutation screening in late-onset diabetes. Nature Genetics 2: 153-156

9. Steiner DF, Tager HS, Chan SJ, Nanjo K, Sanke T, Rubenstein AH (1990) Lessons learned from molecular biology of insulingene mutations. Diabetes Care 13: 600-609

10. Yano H, Kitano N, Morimoto M, Polonsky KS, Imura H, Seino Y (1992) A novel point mutation in the insulin gene give rise to hyperproinsulinemia (Proinsulin Kyoto). J Clin Invest 89: 19021907

11. Taylor SI, Cama A, Accili D et al. (1992) Mutations in the insulin receptor gene. Endocrine Rev 13: 566-595

12. Bell GI, Xiang K-S, Newman MV et al. (1991) Gene for non-insulin-dependent diabetes mellitus (maturity-onset diabetes of the young subtype) is linked to DNA polymorphism on human chromosome 20q. Proc Natl Acad Sci USA 88: 1484-1488

13. Ballinger SW, Shoffner JM, Hedaya EV et al. (1992) Maternally transmitted diabetes and deafness associated with a $10.4 \mathrm{~kb}$ mitochondrial DNA deletion. Nature Genetics 1:11-15

14. van den Ouweland JMV, Lemkes HHPJ, Ruitenbeek W et al. (1992) Mutation in mitochondrial tRNA ${ }^{\text {Leu(UUR) }}$ gene in a large pedigree with maternally transmitted type II diabetes mellitus and deafness. Nature Genetics 1:368-371

15. Griffin LD, Gelb BD, Wheeler DA, Davison D, Adams V, McCabe ERB (1991) Mammalian hexokinase 1: evolutionaly conservation and structure to function analysis. Genomicus 11: $1014-1024$

16. Schwab DA, Wilson JE (1991) Complete amino acid sequence of the type III isozyme of rat hexokinase, deduced from the cloned cDNA. Arch Biochem Biophys 285:365-370

17. Thelen AP, Wilson JE (1991) Complete amino acid sequence of the type isozyme of rat hexokinase, deduced from the cloned cDNA: comparison with a hexokinase from Novikoff ascites tumor. Arch Biochem Biophys 286: 645-651

18. Harison RW (1985) Ph.D. Thesis. Yale University, New Haven 
19. Diabetes mellitus: report of a WHO Study Group (1985) WHO Tech Rep Ser 727, Geneva, pp 1-113

20. Orita M, Iwahana H, Kanazawa H, Hayashi K, Sekiya T (1989) Detection of polymorphism of human DNA by gel electrophoresis as single-stranded conformation polymorphisms. Proc Natl Acad Sci USA 86:2766-2770

21. Kadowaki T, Kadowaki H, Taylor SI (1990) A nonsense mutation causing decreased levels of insulin receptor mRNA: detection by a simplified technique for direct sequencing of genomic DNA amplified by the polymerase chain reaction. Proc Natl Acad Sci USA 87: 658-662

22. Shimada F, Suzuki Y, Taira M et al. (1992) Abnormal messenger ribonucleic acid (mRNA) transcribed from a mutant insulin receptor gene in a patient with type $A$ insulin resistance. Diabetologia 35: 639-644

23. Barker D, Schafer M, White R (1984) Restriction sites containing $\mathrm{CpG}$ show a higher frequency of polymorphism in human DNA. Cell 36: 131-138

24. Magnuson MA (1990) Glucokinase gene structure. Functional implications of molecular genetic studies. Diabetes 39: 523-527
25. Matschinsky FM (1990) Glucokinase as glucose sensor and metabolic signal generator in pancreatic $\beta$-cell and hepatocytes. Diabetes 39: 647-652

26. Meglasson MD, Matschinsky FM (1989) New perspectives on pancreatic islet glucokinase. Am J Physiol 256: E1-E13

27. Velho G, Froguel P, Clement K et al. (1992) Primary pancreatic beta-cell secretory defect caused by mutation in glucokinase gene in kindreds of maturity onset diabetes of the young. Lancet 340: $444-448$

Received: 26 October 1992

and in revised form: 21 December 1992

\section{Dr. H. Makino}

Second Department of Internal Medicine

Chiba University School of Medicine

1-8-1 Inohana Chuo-ku

Chiba 260

Japan 